\title{
Recurrent EBV-Related Lymphoma
}

National Cancer Institute

\section{Source}

National Cancer Institute. Recurrent EBV-Related Lymphoma. NCI Thesaurus. Code C147863.

The reemergence of EBV-related lymphoma after a period of remission. 